International Research Journal of Management, IT \& Social Sciences
Available online at https://sloap.org/journals/index.php/irjmis/
Vol. 6 No. 5, September 2019, pages: 81 88
ISSN: 2395-7492
https://doi.org/10.21744/irjmis.v6n5.709

\title{
Renovated Evaluative Practices
}

Article history:

Received: 27 March 2019

Accepted: 31 May 2019

Published: 22 August 2019

\section{Keywords:}

application;

contemporary trends;

renewed evaluation practice;

significant learning;

teaching-learning;
Yolanda Inés España Bone ${ }^{a}$

Yiria Giovinezza Macías Figueroa ${ }^{\text {b }}$

José Gregorio Lucas Delgado ${ }^{c}$

Mayra Carlina Avellán Avellán d

\begin{abstract}
The evaluation of the learning acquired by the students has been the generative topic of the goals proposed in the teaching-learning process, from the teaching action. The evaluation is stimulating for the multiple intelligences as a thermometer of the degree of understanding of the speakers and the distance between knowledge and academic outdating is abysmal. Establishing as an objective, the application of renewed evaluation practices in the inter-learning process, from teaching, is essential to authentic evaluation. At present, emphasis is placed on contemporary evaluation trends applied by teachers with a view to integrative educational innovation that seeks to strengthen meaningful learning; It is intended to demonstrate the use and application of innovative techniques that guarantee the application of evaluation practices at the forefront so that teachers improve their educational work, with the possibility of improving the educational performance of the speakers. The methodology applied in this research has been field, carried out in the "Cristo Rey" Educational Unit, located in the city of Portoviejo-Manabí-Ecuador, in the period 2019-2020; The instrument for the collection of information was through a succinct survey, through a bank of closed questions that define alternative answers, varying according to the discernment of the teachers surveyed with reference to the treated topic. Observation is an element sine qua non in the present investigation evidenced with entertaining, playful and participatory techniques cooperatively, as an integral part of the process towards meaningful learning.
\end{abstract}

2395-7492@ Copyright 2019. The Author. This is an open-access article under the CC BY-SA license (https://creativecommons.org/licenses/by-sa/4.0/) All rights reserved.

\section{Author correspondence:}

Yolanda Inés España Bone,

Masters student, Pontifica Universidad Católica del Ecuador, Sede Manabí.

Email address: yiespana@cristorey.edu.ec

\footnotetext{
a Pontifica Universidad Catolica del Ecuador, sede Manabí, Portoviejo, Ecuador

${ }^{\mathrm{b}}$ Pontifica Universidad Catolica del Ecuador, sede Manabí, Portoviejo, Ecuador,ygmacias@cristorey.edu.ec

c Pontifica Universidad Catolica del Ecuador, sede Manabí, Portoviejo, Ecuador, lukas812@ hotmail.com

${ }^{\mathrm{d}}$ Unidad Educativa Cristo Rey, Portoviejo, Ecuador, mcavellan@ cristorey.edu.ec
} 


\section{Introduction}

Since the emergence of education, evaluation has been a consubstantial part as a post-learning resource. The way of evaluating was massified and standardized towards a common result: that all achieve excellence from the same quantitative parameters.

At present, evaluation is an indispensable learning process. This axiom includes all the activities and precepts that a teacher must contemplate in the journey of educating infants, public, youth or adults according to their natural condition, their abilities, interests, the rhythm of qualitative learning.

The evaluation is an educational element of the learning circuit concerning feedback and the evaluation itself renewed and applied in the teaching-learning process of teachers. With this data of the didactic and investigative practices, it is foreseen to carry out a detailed and at the same time succinct analysis of the main innovative techniques.

Evaluation is one of the most complex issues with the most impact on the teaching-learning processes. To evaluate means to collect information and value it, in order to understand how the processes are and what the results are. An authentic and renewed evaluation invites us to make continuous improvement decisions based on what we have learned (Calatayud, 2014), with the purpose of achieving the social and personal development of children and young people: planning and systematizing educational actions, which make sense to school educational practice and that entails the need to evaluate the effectiveness of this double school functionality.

\section{Materials and Methods}

By conceptualizing the renewed educational practices of teachers of the "Cristo Rey" Educational Unit, it was possible to demonstrate the information collected through the survey technique, based on a question script with closed answer alternatives, added to the use of references authors in articles, in addition to other bibliographic sources.

Similarly, the scientific-analytical-synthetic method was used from which the theoretical elements related to the evaluation of learning were deepened. To obtain results of the renovate evaluation practice, the sample of 14 teachers from the said educational unit was taken into account. Murray \& Larry (2005), equation (1) was applied for this.

$$
n=\frac{Z^{2} \cdot p q N}{N \cdot e^{2}+Z^{2} \cdot p q}
$$

Where:

$$
\begin{array}{lll}
\mathrm{n} & \rightarrow \text { Sample size (14) } & \\
\mathrm{Z} \rightarrow \text { Confidence level } & 1.96 \\
\mathrm{p} & \rightarrow \text { Positive variability } & 0.5 \\
\mathrm{q} & \rightarrow \text { Negative variability } & 0.5 \\
\mathrm{~N} & \rightarrow \text { Population } \\
\mathrm{e} & \rightarrow \text { accuracy or sampling error } 5 \%(0.05) \text { Support }
\end{array}
$$

Table 1 was taken into account, where the sample size was taken into account by confidence levels.

Table 1

Calculation of the size of a sample by confidence levels

\begin{tabular}{llllllllll}
\hline Certainty & $95 \%$ & $94 \%$ & $93 \%$ & $92 \%$ & $91 \%$ & $90 \%$ & $80 \%$ & $62.20 \%$ & $50 \%$ \\
\hline $\mathrm{Z}$ & 1.96 & 1.88 & 1.81 & 1.75 & 1.69 & 1.65 & 1.28 & 1 & 0.6745 \\
$\mathrm{Z}^{2}$ & 3.84 & 3.53 & 3.28 & 3.06 & 2.86 & 2.72 & 1.64 & 1,00 & 0.45 \\
$\mathrm{E}$ & 0.05 & 0.06 & 0.07 & 0.08 & 0.09 & 0.10 & 0.20 & 0.37 & 0.50 \\
$\mathrm{e}^{2}$ & 0.0025 & 0.0036 & 0.0049 & 0.0064 & 0.081 & 0,01 & 0,04 & 0,1369 & 0,25 \\
\hline
\end{tabular}




\section{Results and Discussions}

According to the analysis carried out through the formula for the application of the survey, a sample of 14 teachers from the Elementary and Middle sub-level was taken.

a) Evaluation batteries: The use of evaluation batteries by teachers leads to responses in a high percentage: $86 \%$. This data does not determine the quality of the batteries, if it is for objective items of closed questions or if it gives way to a more qualitative analysis of creative, open answers, with possibilities of suggestion or expression of the student, even giving way to correction and learning experiential

b) $98 \%$ of teachers surveyed plan their evaluations. $100 \%$ apply them to their students. This information is very timely because it eliminates the surprise effect. But the question regarding the application of "surprise" evaluations leaves a margin of doubt about the traditional evaluation without taking into account the agreements, the sharing, the dialogic evaluation, the feedback, the reinforcement, the error-based learning as Innovation mechanisms

The institutional objective with innovation is the management of techniques and methodology that is active, participatory and evaluatively growing, that maintains a learning rhythm with inferences and metacognitive reflections on how I learn, unlearn and relearn, where there are no evaluative surprises because they detract respect from the student evaluated.

c) Reaffirming the above statements, it is inferred that teachers handle error-based learning and feedback very well as a way of learning and relearning. When the group takes me or I take it, times are optimized, stress is released, times can be managed, creativity and the result will always be more productive and fun than if we were alone. The group sets the pace and maintains the feeling of success keeping it as a possibility of growth and increase of self-esteem.

d) Processes and results: Within the active methodology, $100 \%$ of teachers use methodological innovation skills. But the number of other skills varies according to their use and student needs. The exposures on the part of the infants and the participation of the metacognition ladder in $90 \%$ is gratifying for the present evaluative analysis, since the routines favor the analysis, experimentation, and application of the knowledge and skills assumed with the approach Humanistic and social benevolence, with a high level of use of the game and gamified rules.

\section{Learning approaches}

Approaches have a predisposition and orientation character to learn in a certain way, with learning styles. Students have their own thoughts, their independence, their multiple ways of internalizing knowledge, due to their amalgamated intelligence; but, also with its own gregarious characteristics.

It is always intended as an intrinsic purpose to achieve the acquisition of learning; and the evaluation fulfills its leading role in the works related to the competences, evidenced in the concern to understand the meaning of the task, incoherence to what has been learned and the evaluations maintain the rigor and weight that it deserves.

The relationship between what is taught, how it is taught and the mode of evaluation must be clear and coherent for students in the teaching-learning process and that the evaluations favor this process.

Regarding the quality of education through evaluation, it is necessary to specify that what is learned is evaluated... not only what has been taught; and less cognitive skills, only. To achieve true learning; evaluate it or feed it back through contextualization, evaluation is promoted as an instrument of continuous improvement. The evaluation so that it fulfills its educational objective must be designed, implemented, communicated and achieved as a majestic transformation (Zambrano Diaz, 2014).

\section{What are competencies?}

The purpose of the student learning process is to know if the required learning that accredits it for the succession of the next school years or for the acquisition of a degree, as the case may be, has been taken into account. Aspects related to educational evaluation and its integrity, continuity, regulation, and orientation, in addition to the flexible part.

In this renewed evaluation process, competencies play a very important role, being understood as a combination of skills, knowledge, attitudes, and aptitudes, and available to inclusion to learn, in addition to knowing how the key competencies represent a multifunctional and transferable role of knowledge and skills that all individuals need for

Bone, Y. I. E., Figueroa, Y. G. M., Delgado, J. G. L., \& Avellán, M. C. A. (2019). Renovated evaluative practices. International Research Journal of Management, IT and Social Sciences, 6(5), 81-88. 
their personal development. It is nothing more than internalizing knowledge and recognizing its importance and the contribution they have in problem-solving and decision making.

\section{How to evaluate competencies?}

Changes in the evaluation are necessary, because of the direct relationship between the competences and the learning outcomes or achievement indicators, since they are at a didactic crossroads (Cano, 2008), the result or effect of a learning process is assessed by complying with a summative mission, but at the same time as development of the competences of the student.

Educational competencies allow information to be collected parallel to learning, in addition to considering achievement indicators, depending on the different levels of performance or mastery.

To carry out this process, the student must be given information about their achievement levels permanently, so that they are aware of the acquired ones and take the necessary corrective measures for their learning.

Self-assessment, evaluation and hetero-evaluation should be used to promote reflection on learning processes, (Ayala et al., 2014), evidence and level of performance, focused not only on knowledge but also on Knowledge and Knowing how to be, the motivation must reach the student addressed to these three aspects with these three evaluative judgments with the central axis of the hetero-evaluation that is responsibility as value and as subjective and objective performances: experience, knowledge, previous knowledge and those acquired.

A proposal of precise evaluation that, the action of the student is of effective experiences in the resolution of daily and significant problems that allow testing the complex reality of the social life and even future professional. The consensus, the opportunities, the follow-up of these opportunities, the active and collaborative participation, the controversy through a stealthy debate in camaraderie leads to revalue the subjective and objective learning to make them meaningful, with the didactic component of the consolidation of the learning (Muñoz et al., 2016).

Every teaching process requires information gathering (documentation); analysis and assessment of information (awareness); Move the analysis and assessment (feedback); establish measures and improvements (learn to learn) in order to favor students, highlighting the evaluation as an element of individual or group positive improvements.

Table 2 shows the processes of the role of the teacher and the student in the teaching-learning system.

Table 2

Processes in the teaching-learning system

\begin{tabular}{|c|c|}
\hline Teacher's & Role Student's role \\
\hline $\begin{array}{l}\text { Teach and motivate their students. Create an atmosphere } \\
\text { that invites you to research, learn, and build your own } \\
\text { learning, covering intangible and symbolic issues. } \\
\text { - It uses a large number of interactive resources and } \\
\text { new technologies to get the apprentices to better } \\
\text { understand the contents and capture their attention. } \\
\text { - Feed the curiosity of the students. } \\
\text { - Challenge the knowledge learned through games } \\
\text { and activities that come out of the "routine." } \\
\text { - It encourages the participation and interaction of its } \\
\text { students. } \\
\text { - Seek to answer your questions with your valid } \\
\text { arguments. } \\
\text { - Use techniques such as debate so that your students } \\
\text { are able to assimilate the contents, make their own } \\
\text { ideas about a given topic. }\end{array}$ & $\begin{array}{l}\text { It is an active part of this teaching-learning process. } \\
\text { - You must be creative, empowered, and thoughtful. } \\
\text { - Being able to build their own knowledge with all } \\
\text { the tools acquired for their well-being. } \\
\text { - It links time, space, technology, society, progress, } \\
\text { transition and restructuring of the system as } \\
\text { required by educational efficiency and } \\
\text { effectiveness. }\end{array}$ \\
\hline
\end{tabular}

Source: (Valladares, 2008). 
Conceptualizing renewed evaluation practices

The education that a teacher wishes to achieve by being innovative constitutes a whole platform to assume his role. One of the evaluative axioms with which the teacher manifests, from his daily practice, is directed towards the direct application of the learning circuit with the innovative "inverted classroom" preceptor whose principles deontological harmonize with the whole process and the preparation of mental models Towards the demonstration that entails doing a metacognition process follow-up.

a) The first is to turn the class into an investigative reading possibility, where the student inquires about a topic indicated by the teacher with a virtual page or route and leads his doubts to be resolved in the second moment in class.

b) This second moment occurs with the questioning preparation that the student has been applying the key concepts and the feedback assumed by the teacher.

c) The third moment is with greater freedom and a lot of responsibility: the apprentice reviews everything learned and generalizes the built knowledge. In this way, the conceptual framework of development expands and gives way to innovation not as a methodology, but as a "modus vivendi".

\section{Some renewed evaluation practices}

Education to be consistent with the methodological process and its conceptual framework must continue the vital and contextual lines in everyday life to the infant. For this reason, it is essential to record this evaluation step along with the process methodology and the conceptualization of experienced or evidenced cognitive theories. In table 3 , a few and succinct are detailed:

Table 3

Renovated educational practices

Practices

Project-based learning $\quad$ It is a work methodology applied in the classroom, for the development of skills. It proposes to the students individually or in a group a final challenge that is materialized in the elaboration of a product whose steps are applied in a practical and gradual way in the knowledge of the learning areas immersed in the project.

Cooperative Learning Consists of working together to achieve common goals, it is nothing but the didactic use of the reduced work team, where students work together to maximize their own learning and that of their peers.

Educational Portfolio It is a tool that allows sequenced and orderly work and facilitates the process of reflection and improvement, (Garay, 2015). It is especially indicated in the continuous evaluation since it evidences the process itself and allows it to be evaluated along with the results.

Rubrics They are evaluation protocols that facilitate the assessment and qualification through the use of criteria of merit, learning, knowledge and/or skills achieved by students in an activity, (Del Pozo, 2014), is a document which describes different levels of quality of a task or product.

Problem-based It is a methodology of work based on the classroom that, due to its approach, is ideal for learning. the development of competences (Del Pozo, 2014; Dalal, 2016). It proposes to the students individually or in a group a final challenge that is materialized in the elaboration of a product, through a series of steps similar to those of the management of a project, to apply them in a practical and gradual way in the immersed learning areas in the project.

Self Assessment and This technique favors reflection on the group and own performance. It can be used in Peer Evaluation any grade of Basic Education and the instruments used are varied. We have reflective focus questions.

Pecha Kucha It is a presentation format that exposes the result of a project through images, mainly. 20 slides are exposed, and each one presents orally for 20 seconds. It was invented by architects Astrid Klein and Mark Dytham in 2003

Bone, Y. I. E., Figueroa, Y. G. M., Delgado, J. G. L., \& Avellán, M. C. A. (2019). Renovated evaluative practices. International Research Journal of Management, IT and Social Sciences, 6(5), 81-88. https://doi.org/10.21744/irjmis.v6n5.709 
Thought Routine

Skills

Graphic Organizers

Exhibitions and Creative Presentations

Diary and learning $\log$.

Test.

Observation
These are structures with which students, individually or collectively, initiate, discuss, manage their thinking at the same time. (Del Pozo, 2014). These are short and easy-tolearn strategies that guide students' thinking and structure classroom discussions.

These are mental abilities and processes that allow the individual to develop the ability to: observe, analyze, reflect, synthesize, make inferences, analogies, be creative, these abilities focus on adapting their environment and solving problems that develop the critical thinking. (Del Pozo, 2014). They are easy to develop as a method of learning in children, allowing them to appropriate, first of elementary knowledge.

These are hologram diagrams and structures of thought. They try to explain the form and order by which an idea is presented and its real expression: the activity of the class, its logic of thought and its logical sequence. For children, it is known as the "house of ideas."

They are the basis of innovation. It is through these expressive practices that the student enables the communication of what he knows and systematizes the way in which his thinking manifests and feels motivated. For this, it is necessary to motivate, stimulate, plan, evaluate and systematize the didactic and educational logic.

They are written records that can include graphics and are made during the task that was developed in the unit, in one year. This resource allows teachers to assess student progress. It is also useful for students to evaluate themselves.

It is a written, generally short text that analyzes personal interpretation on a given topic, be it: philosophical, scientific, historical, literary, social, (Vásquez, 2005), predominantly personal and subjective from the author's point of view.

It serves to informally evaluate behaviors, attitudes, abilities. Direct observation is a way of focusing the look descriptively of what happens in a given time.

Source: (Foundation, 2018)

Deontology is not a mere speech; It is in-depth the transformation of the teacher towards the highest ends in educational response through the qualitative evaluation as the growth of the "I" towards "otherness" as part of the inclusive, equitable and growing transforming curriculum (Navarro et al., 2017).

\section{Decision making based on renewed educational practices}

Decision making is a real challenge in the teaching-learning process, this formative evaluation process also considers it necessary to qualify the basic levels of intellectual knowledge, together with the achievements, skills, and goals of understanding developed, based on capacity, age and limitations Decision making is the choice made to solve a problem situation, generated in a given time frame, be it at family, school, social, business and even sentimental, to which different points of view should be considered as possible solutions and perform the necessary classification, always opting for the best option.

This decision must be evaluated between the fixed and probable risks, or those that do not show predictable results, without neglecting the decisions made under a group organizational structure (Carvajal \& Valencia, 2016), the theory of decision making analyzes, how an individual (student) directs suitable results, according to their priorities.

It is the processing and interpretation of a reflection necessary for the teacher to provide maximum help to the student; from a teleological vision with the opportunity to grow "beyond" their cognitive limits, taking into account their age, abilities and prior preparation, which allows the teacher to adapt to the uniqueness of the learners.

According to Del Pozo (2014), Decision making is a thinking skill that has several options and its possible consequences when a decision is to be made, for this, it is necessary to consider the following questions that will be clarified once Begin the decision process to make:

a) What makes the decision necessary?

b) What are the options?

c) What are the consequences of each option?

d) How important are the consequences?

e) What is the best option according to the consequence? 
The key to this skill is to establish a direct relationship between the thought that is intended to be taught and the students' experiences. In the process of the following analysis and discussion of the results obtained through the survey applied to 14 teachers of the Middle Level of the General Basic of the Educational Unit Cristo Rey, of the city of Portoviejo.

According to the results, it is revealed that $100 \%$ of the teachers surveyed apply the renewed evaluation practices with the speakers as part of the innovative methodology used in their hours of daily classes, $86 \%$ work with structuredbased evaluation batteries in the classroom they work, being used mostly in the quarterly evaluations as part of the ministerial requirements. In the same way, it can be evidenced that $93 \%$ devotes time to the evaluation preparation in their planning day in order to boost the classes taught. While $100 \%$ dedicates time to the evaluation in the academic day with the students, the same $100 \%$ corresponds to the evaluation in their teaching activities that are part of a continuous process. A divided percentage resulted in the questioning of whether they conduct surprise evaluations with their students, which are located at $43 \%$ Yes and 58\% No, which leaves as a result that these evaluations are handled with prior notices and with knowledge of the students. At the top of the percentage is the evaluation of the evaluation processes and results of its students. Another $100 \%$ believe that cooperative evaluations can become significant learning moments. Another of the data reflected in the survey is that once the results of the evaluation practices have been obtained, $86 \%$ perform the corresponding feedback in order to weigh the students' knowledge.

\section{Conclusion}

The methodology of evaluative innovation from teachers to students is conveniently applied as part of the systematic and significant methodological process, becoming an evaluative culture.

The teacher who has been immersed in a traditional system proposes a paradigm shift by knowing and motivating with the methodology, giving meaning to what he teaches and evaluates, through believing in the transformation of the learner.

There is a positive attitude of transformation that favors the application of innovative methodologies in teachers when they observe and apply these thinking skills or routines by increasing the reflective levels of their students, they do not want to return to the traditional system. Both teachers and speakers are new people, new learners in an inclusive world.

\section{Conflict of interest statement}

The authors declared that they have no competing interest.

\section{Statement of authorship}

The authors have a responsibility for the conception and design of the study. The authors have approved the final article.

\section{Acknowledgments}

The authors would like to thank the editor of IRJMIS for their valuable time, support, and advice in completing the present paper.

Bone, Y. I. E., Figueroa, Y. G. M., Delgado, J. G. L., \& Avellán, M. C. A. (2019). Renovated evaluative practices. International Research Journal of Management, IT and Social Sciences, 6(5), 81-88. 


\section{References}

Aranda, E., Valladares, M., Martinez-Villacampa, M., Benavides, M., Gomez, A., Massutti, B., ... \& Dueñas, R. (2008). Randomized study of weekly irinotecan plus high-dose 5-fluorouracil (FUIRI) versus biweekly irinotecan plus 5-fluorouracil/leucovorin (FOLFIRI) as first-line chemotherapy for patients with metastatic colorectal cancer: a Spanish Cooperative Group for the Treatment of Digestive Tumors Study. Annals of oncology, 20(2), 251-257.

Ayala Zuluaga, CF, Nore, O., Fredy, J., Zuluaga, A., \& Enver, J. (2014). Assessment Practices as a Holistic Process. Folios , (40), 31-44.

Calatayud, M. (2014). Evaluation of teaching practice and educational quality: a chained relationship. Iberoamerican Education. Retrieved from https://dialnet.unirioja.es/servlet/articulo?codigo $=5876257$

Cano, E., Lafuente, D., \& Bastidas, D. M. (2010). Use of EIS for the evaluation of the protective properties of coatings for metallic cultural heritage: a review. Journal of Solid State Electrochemistry, 14(3), 381-391. https://doi.org/10.1007/s10008-009-0902-6

Carvajal, G., \& Valencia, G. (2016). Decision making in the school classroom. Educational pen. Retrieved from http://revistasum.umanizales.edu.co/ojs/index.php/plumillaeducativa/article/view/1750/2648

Dalal, R. S., \& Sharma, S. D. (2016). Political dimension of Indian federal system: an evaluation. International research journal of engineering, IT \& scientific research, 2(7), 25-33.

Del Pozo, M. (2014). Intelligent learning. Tekman Books

Fundación, M. (2018). New tools for authentic evaluation. Obtained from www.fundaciónmapfre.org

Garay, J., Kiayias, A., \& Leonardos, N. (2015, April). The bitcoin backbone protocol: Analysis and applications. In Annual International Conference on the Theory and Applications of Cryptographic Techniques (pp. 281-310). Springer, Berlin, Heidelberg.

Muñoz Olivero, JA, Villagra Bravo, CP, \& Sepúlveda Silva, SE (2016). Teachers' Reflection Process to Improve Learning Assessment Practices in the Context of Education for Youngsters and Adults (EPJA). Folios , (44), 7791.

Navarro Mosquera, N. G., Falconi Asanza, A. V., \& Espinoza Cordero, J. (2017). Improving the evaluation process of students in basic education. revista universidad y sociedad, 9(4), 58-69.

Spiegel, MR, \& Stephens, LJ (2000). Statistics: Schaum Collection . Bookman

Vásquez, F. (2005). Ask the essayist. Bogotá: Kimpres .

Zambrano, A., Huerta, M., Diaz, M., de Andrade, M., \& Marchena, P. (2009). Quality of Service Evaluation of Telemedicine Network Design with IEEE 802.11 b Technology. In World Congress on Medical Physics and Biomedical Engineering, September 7-12, 2009, Munich, Germany (pp. 218-221). Springer, Berlin, Heidelberg. https://doi.org/10.1007/978-3-642-03904-1_61 